\title{
"QUALÉ a desse ÓRGÃO??? arte-reflexão sobre 0 amor
}

Alessio Di Pascucci ${ }^{1}$

Marília Pinto Petrechen ${ }^{2}$

Mariângela Scaglione Quarentei ${ }^{3}$

O artista olha para o mundo e vê coisas nas quais olhos apressados não se detêm. Ele busca capturar, com esse olhar mais contemplativo e investigativo, os sentidos ocultos na superfície dos fenômenos da vida, para, a partir das suas observações, criar livremente o campo da sua expressão.

Quando um artista olha para a expressão do amor, na sua vivência amorosa e na vivência amorosa dos que o circundam, e vê algo em comum entre elas, percebe que há um ruído na orquestração da melodia amorosa. Notando esta estranha sonoridade desarmônica vinda de interditos na forma de negação do compartilhamento do sensível, vinda do medo de tudo o que a intimidade do sentimento amoroso pode gerar de mudança na textura dos afetos e na subjetividade dos indivíduos, esse artista é tomado por um desejo de compor criativamente algo que expresse as reflexões dessas percepções.

A intervenção artística "Qualé a desse órgão?" propõe uma reflexão sobre essa dificuldade dos encontros amorosos na sociedade atual. A observação do estranho paradoxo entre o desejo de entrega e estratégias de recuo dos afetos foi a fonte das duas perguntas que se encontram colocadas no material gráfico produzido pelo NUAS - Núcleo de Arte Solta:

\section{- "Do que ele tem medo?"}

\section{- "O que ele está sentindo agora?"}

Essas frases, junto à imagem de um coração, foram coladas em locais públicos de diversas cidades brasileiras, com a intenção de criar, nos observadores em trânsito, uma pausa reflexiva sobre suas capacidades e condições afetivas. Se perguntar sobre os próprios sentimentos, se perguntar sobre do que se tem medo e enfrentar seus afetos, são questões fundamentais, nas quais todo o indivíduo deveria se deter para produzir uma ampliação na qualidade da sua expressão afetiva.

1-3 NUAS - Núcleo de Arte Solta.aledipascucci@gmail.com http://www. nucleodeartesolta. blogspot.com 
Em uma sociedade em que, ainda, os padrões de afetividade e expressão de amorosidade conduzem os corações em direção a um modelo precário para produção de potência, saúde plena e alegria do músculo do amor, é necessário pulsar o pensamento e refletir sobre essa pulsão vital na composição das relações de partilha afetiva expressada no encontro entre o eu e o outro: o Amor.

A pequena esfera onde acontece a dinâmica da troca dos afetos entre o eu e o outro é a base da construção do sentido de humanidade. Se quisermos, de fato, construir uma humanidade mais amorosa, teremos de produzir alterações significativas na nossa individual expressão de amorosidade.

"Qualé a desse órgão?", intervenção artística em espaços públicos, quer criar ressonâncias no pensar: a ideia de que os indivíduos são dotados da capacidade de produção de sentimento amoroso e que, quando esse sentimento não segue o seu ciclo natural de fluidez nos encontros, seja por medo ou desconhecimento de suas próprias emoções, o indivíduo adoece em sua alma. E as almas doentes geram corpos e mentes doentes, que produzem uma sociedade na qual se negligencia a importância da expressão do amor na construção da saúde individual e coletiva.

Sociedade doente?

Do que tem medo?

O que sente agora?
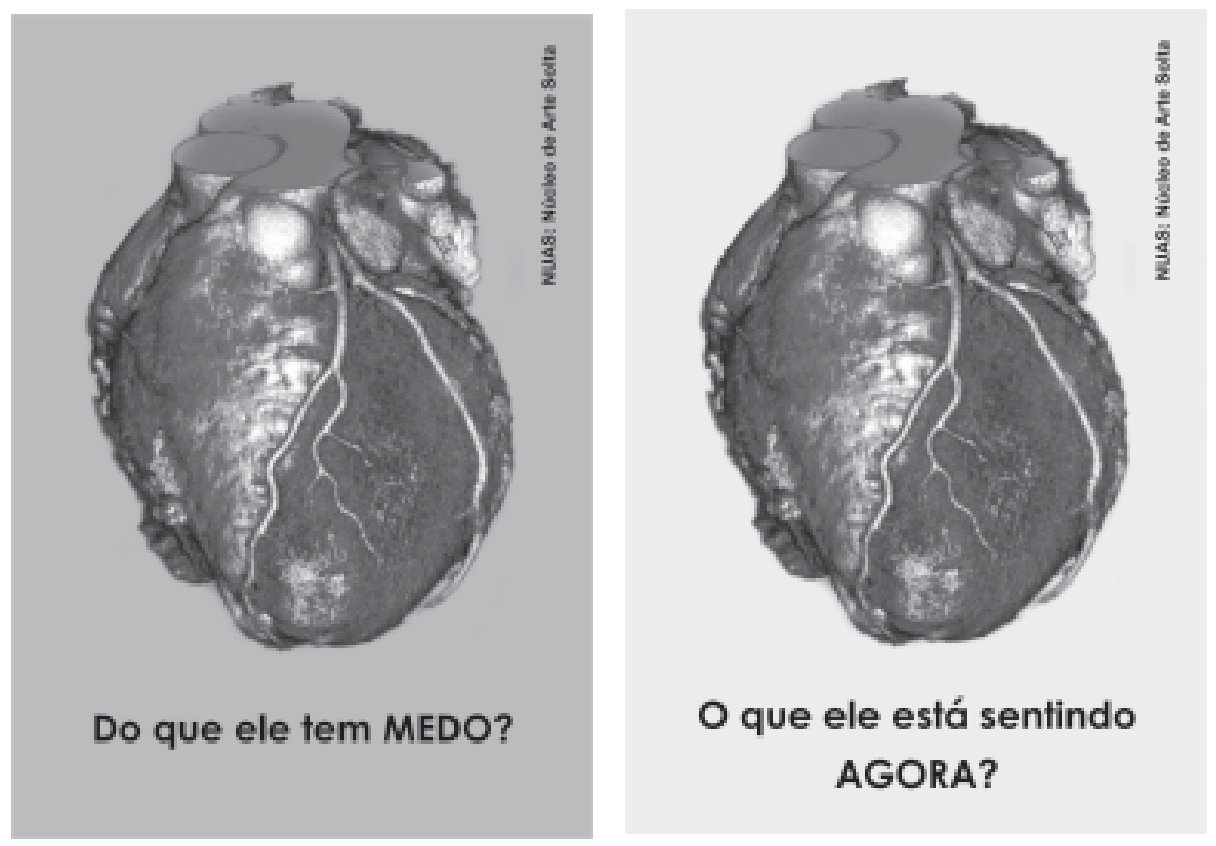

\section{NUAS - Núcleo de Arte Solta www.nucleodeartesolta.blogspot.com}

O NUAS é um dispositivo estratégico para a realização de encontros criativos. Não como um "coletivo de artistas", mas um colo-ativo para embalar, com afetos, as ideias que querem se transformar em arte solta.

Idealizado pelo artista multimídia Alessio Di Pascucci, surgiu do desejo de composições artísticas com outras pessoas. Tem, em sua ideia original, o nãocomprometimento com ser um grupo fixo, mas ser um grupo mutante, aberto, flutuante, em que pessoas se propõem a partilhar corpos e agregar ideias geradoras de vida e arte solta; muitas vezes, de arte-pública. 
${ }^{3}$ DELEUZE, G. ¿Que és un dispositivo? In: BALIBAR, E. et al. (Orgs.). Michel Foucault, filósofo. Trad. Wanderson Flor do Nascimento. Barcelona: Gedisa, 1990, p.155-163.

${ }^{4}$ CASTRO, E. Vocabulário de Foucault: um percurso sobre seus temas, conceitos e autores. Trad. Ingrid Müller Xavier. Belo Horizonte: Autêntica, 2009. p.124.

${ }^{5}$ DELEUZE, G.

Conversações, 1972-1990. Rio de Janeiro: Ed. 34, 1992. p.156.

${ }^{6}$ DELEUZE, G Conversações, 1972-1990. Rio de Janeiro: Ed. 34, 1992 p.157
Tomamos o conceito de dispositivo lançado por Foucault e discutido por Deleuze para falar do NUAS enquanto território-máquina de "fazer ver e fazer de falar" ${ }^{3}$, como uma "rede de relações que podem ser estabelecidas entre elementos heterogêneos: discursos,..., regramentos, proposições teóricas, filosóficas, morais, o dito e o não dito. [...] Trata-se de uma formação que, em um momento dado, teve por função responder a uma urgência" 4 . Urgência esta que facilmente associamos à vontade de enunciar por parte de seus integrantes e do conteúdo expressado. Algo urge ser atualizado pelos seus proponentes, tornando-se causa e/ou efeito daquela junção para efetivar performances ou atos artísticos.

O NUAS existe quando algo acontece e com quem acontece: uma ideia, vontade ou impulso se gera e agencia outros e modos para ganhar o mundo. Ele existe na ação, é ação, é fabricação de intercessores, como nos diz Deleuze: "o essencial são os intercessores. A criação são os intercessores. [...] é preciso fabricar seus próprios intercessores" 5 e "O que é preciso é pegar alguém que esteja "fabulando", em flagrante delito de fabular. Então se forma, a dois ou em vários, um discurso de minoria. [...] pegar pessoas em flagrante delito de fabular é captar o movimento de constituição de um povo. De certa maneira, o povo é o que falta"6.

Enquanto campo de forças, o NUAS atua como ponto de congruência de encontros para ampliar as formas expressivas de seus integrantes e de sua estética, mas pretende, a partir de então, dissipá-los, dispersálos, espalhá-los no campo social.

Algumas ações do NUAS:

Qualé a desse Órgão? - colagem de material gráfico em locais públicos, 2011 - Botucatu - SP; Araraquara - SP; Amparo - SP ; São Paulo SP e Curitiba-PR.

Colagem de material gráfico/sticker art com a imagem de um coração junto às perguntas: "O que ele está sentindo agora?" e "Do que ele tem medo?" - como proposta de reflexão sobre o amor e os afetos.

Quanto pesa seu coração? - performance reflexiva sobre o sofrimento amoroso, 2011 - Curitiba-PR.

No Largo da Ordem, no período do Festival de Teatro de Curitiba, o performer, segurando um coração de verdade, perguntava às pessoas do local se elas poderiam ajudá-lo a carregar o seu coração, que estava tão "pesado".

Banco dos Encontros - intervenção de oficina teatral, 2011 - Botucatu-SP. Instalação pública, com temática sobre a liberdade, realizada por adolescentes participantes da Oficina Teatral Ações Soltas, coordenada por Alessio Di Pascucci no Ponto de Cultura Espaço Notívagos.

Fonte de Renda - reflexão sobre a distribuição de renda no país, 2011 Botucatu-SP.

Instalação pública que ocorreu durante a Virada Cultural Paulista em Botucatu. Uma fonte abandonada numa praça da cidade foi "vestida" com tiras de renda enquanto eram distribuídos pedaços de renda às pessoas presentes no local. 
Economia Lúdica - ação-reflexão sobre o valor das coisas, 2010-2011 - Botucatu-SP.

Vendas de livros de poesia e produções artísticas nas ruas da cidade, em que os interessados determinavam quanto deveriam pagar.

\section{Vão-se os sonhos e ficam os trajes - uma reflexão sobre o abandono amoroso, 2010 -} Botucatu-SP.

Performance-instalação realizada no MAC Itajahy Martins, Museu de Arte Contemporânea de Botucatu. Entre vestidos de noivas de mulheres que foram abandonadas no altar, ao som de música tocada por dois instrumentistas, o performer constrói um corpo cênico a partir da vivência do abandono amoroso.

Poesia sem gaiola - ação solta sobre a liberdade poética, 2010 - Botucatu-SP

Em praças da cidade, poesias eram lidas e distribuídas.

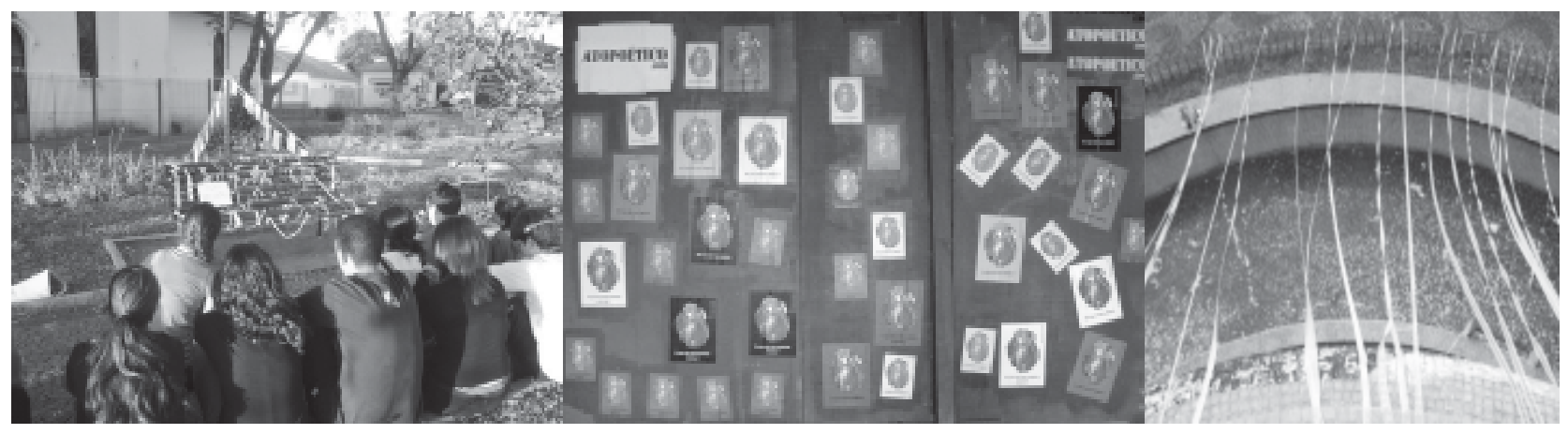

\section{Sobre os autores}

\section{Alessio Di Pascucci}

Artista multimídia, nascido e residente na cidade de Botucatu, interior de São Paulo, atua no fazer artístico desde a década de 1980. No teatro, artes plásticas, dança, vídeo, música e literatura desenvolveu inúmeros trabalhos, entre eles: dramaturgia e direção das peças "Abandono em Branco" e "Beckettianas" (Teatro); exposições "Des-Fotos"e "Vão-se os sonhos, ficam os trajes" (Artes Plásticas); composições gravadas em cds de vários intérpretes e premiações no festival Botucanto (Música); publicação dos livros "Pele" e "Letras Lúdicas" (Literatura) e várias intervenções de rua em performances.

\section{Marília Petrechen}

Performer, pesquisadora e psicóloga. Realiza performances em espaços públicos em diversas cidades brasileiras. Foi intérprete-criadora do espetáculo "À beira de um lugar", 2010 e atuou como produtora cultural e educadora na OSCIP CIRCUS- Circuito de Interação de Redes Sociais e no Ponto de Cultura Galpão Cultural- Assis-SP.

\section{Mari Quarentei}

Libriana nascida na Paulicéia, vive entre São Paulo e Botucatu - um interior ... e nos últimos três anos incluiu Curitiba nesse circuito. Terapeuta ocupacional, arte-educadora, terapeuta corporal e acadêmica independente. A micropolítica: uma grande paixão que inspira estudos contemporâneos da subjetividade, criação coletiva (convívio e partilha), ativismo cultural e a apreciar intensamente a filosofia da diferença.Viver com a arte é coisa antiga, como desenhar, contar estórias, fazer máscaras, escrever quase-poesia e, nesse quase encontra a liberdade. É editora de Criação da Interface, atua no Coletivo de Estudos de Terapia Ocupacional e Produção de Vida, CineclubeParatodos, NUAS e produz saraus caseiros.

Vídeos e mais informações: http//www.nucleodeartesolta.blogspot.com

Contato: aledipascucci@gmail.com 